\title{
Meeting the Students' Expectations: Evaluating the Implementation of English Language Teaching Curriculum
}

\author{
Djuwairiah Ahmad, Faculty of Education and Teacher Training, Universitas Islam Negeri (UIN) Alauddin \\ Makassar, Indonesia, djuwairiah.ahmad@uin-alauddin.ac.id \\ Mardiana, Faculty of Education and Teacher Training, Universitas Islam Negeri (UIN) Alauddin \\ Makassar, Indonesia, mardiana.nurdin@uin-alauddin.ac.id \\ Kaharuddin, Faculty of Education and Teacher Training, Universitas Islam Negeri (UIN) Alauddin \\ Makassar, Indonesia, andi.kaharuddin@uin-alauddin.ac.id
}

\begin{abstract}
Educational institutions are in need of increasing their high standards as an essential factor in improving the level of quality in education. Hence, they are looking at better ways to develop such a curriculum which reaches the pre-decided standards. This calls for curriculum evaluation. This study was aimed at evaluating the implementation of the 2010 Curriculum (K-10) of English Education Department at the Universitas Islam Negeri Alauddin Makassar, Indonesia. The research design adapted Stake's Countenance Model. The data collected were quantitative and qualitative data. The findings revealed that at the transactions stage, the concordance level between the objective conditions and the standard actuality/objective intensity objective for the curriculum implementation components was overall classified as 'Medium' (Score 48.75\%). It indicated that some of the subcomponents still required limited changes or revisions in accordance with the Indonesian National Education Standards Agency instructions. Thus, the formative evaluation of the department's curriculum implementation needs to be conducted periodically (annually) to ensure the quality of the program and anticipate the changes and development of workplace needs.
\end{abstract}

Keywords: Curriculum Design, Curriculum Evaluation, ELT Curriculum Received: 04.12.2020 Accepted: 13.01.2021 $\quad$ Published: 05.02.2021

\section{INTRODUCTION}

In all educational institutions such as schools and universities, curriculum plays a vital role in providing knowledge and skills to all students in the institutions assisting them in the development of desirable, useful knowledge and skills to be applied in their real social daily life (Kaharuddin, Ahmad, D, Mardiana, Rusni 2020). As for many educators, curriculum is conventionally regarded as the planned pedagogical activities offered to the students under the guidance of teachers at schools (Andi, K., \& Arafah, B. 2017, Kaharuddin, Hikmawati, Arafah, B. 2019). The pedagogical activities are carried out by teaching the students a systematic reconstruction of knowledge and experiences to achieve particular formulated goals and better outcomes for the students' continuous and willful growth in academic, personal as well as social competences (Kaharuddin, A. 2018, Arafah, B., \& Kaharuddin, 2019). All educational institutions today are making effort to increase their education standards as an essential factor in improving the quality of education given to their students (Ahmad, D. 2016, Kaharuddin., \& Hasyim, M. 2020). In this regard, they keep searching new and better ways to develop their educational curriculums which are able to meet the high standard in education (Arafah, B., Thayyib, M., Kaharuddin, \& Sahib, H. 2020). This effort consequently calls for a change in the way education is imparted, the teaching methods are implemented to make sure that the education system in the institutions runs effectively (Ismail, A. H. S., Halidin, A., \& Amzah, N, Kaharuddin 2020). For the reason, evaluating curriculum is crucially important to determine the extent to which their current pedagogical programs and their implementation have produced positive and satisfactory outcomes for their students (Yassi, A. H. \& Kaharuddin, 2018, Kaharuddin, K., \& Rahmadana, A. 2020).

English Education Department (called PBI) at the Alauddin State Islamic University of Makassar as one of departments organizing English Education program has designed and enacted the study program curriculum since its establishment in 1998. Previously, this department was named Jurusan Tadris Inggris with Diploma III stratum. The change of name and stratum to S1 mandates the program to make changes to the curriculum and has designed at least three curriculum types. From 1998 to early 2004, it was implemented a curriculum with a meaningful approach. In late 2004, a competency-based curriculum was adopted and started to be used by the students for the intake in 2004 to 2010 . At the end of 2009 , the 
curriculum was re-designed by a consortium producing the 2010 Curriculum (called K-10) and was still competency-based. This curriculum started to be used by the students for the intake in 2011 till now.

The curriculum changes follow the development of higher education needs and summative evaluation findings (Bahar, A. K., \& Latif, I. 2019). As for K-10 implementation, the evaluation plan is formative evaluation with responsive model along with associative tracking. This curriculum document evaluation study focuses on program implementation as part of the curriculum that has been implemented since 2010. The objective of formative evaluation is directed to the improvement of certain parts of the curriculum being development.

In terms of the learning implementation and learning achievement assessment, it was also found some specific problems. These issues include the uniformity of lecture-based learning methods and group discussions that ignore the students' individual differences and characteristics from class to class (Ahmad, D. 2012). In the assessment, it was also found that many lecturers did not return students' assignments and also did not give feedback as an explanation of the meaning of the score given.

Theoretically, these research findings are useful as reference information to improve the 2010 Curriculum implemented in PBI UIN Alauddin Makassar. In addition, the findings may also provide a reference to the similar research in the future. Practically, the findings are also useful to solve the problem of information needed to improve the quality of the 2010 Curriculum implemented in the department, as well as a guide in aligning the findings of curriculum evaluation with students' learning needs for the authorities in developing curriculum and syllabus. Therefore, the paper is then structured as follows: section 2 provides literatures related to the topic. Section 3 outlines our methodology used for analyzing Business Revenue Residual Sharing System in the cooperative. Section 4, the analysis of curriculum (K-10) implementation at the Department of English education is described to show how this curriculum is implemented by reviewing the data on Lecturers' Presence, Learning Process, Learning Assessment, and Student Services. Finally, section 5 provides conclusions and recommendations.

\section{LITERATURE REVIEW}

\section{Basic Concepts and Definition of Curriculum}

Curriculum can be understood by refining the basic concepts or ideas that underlie the term. The initial assumption underlying the birth of curriculum is that science has natural characteristics and skeletons. People will find it difficult to acquire knowledge if the components are scattered and not organized into a systematic structure. The compilation of science components in the form of a systematic structure to be taught to others is what then inspired the birth of curriculum.

Candlin (1984) stated that curriculum is also related to the planning, evaluation, implementation, management, and administration of educational programs. Furthermore, Nasution (2004: 8) also stated that curriculum is something planned as a grip to achieve educational goals. On the other hand, Stenhouse (1975: 4) stated that the different aspects of curriculum must be structured in such a way that the curriculum document is not only poured in practice, but also opens space for evaluation.

\section{Curriculum Evaluation}

Curriculum evaluation is designed to determine the value of curriculum. In the process, evaluation involves assessing to set quality standards with certain criteria, deciding on the choice of relative or absolute quality standards, gathering relevant information, and applying standards to determine value and quality (Simons 1987 in Marsh, 2004: 106; Nichols et al., 2006; and Brown, 1989: 223 in Brown, 1995: 218). Curriculum evaluation is conducted to answer the question of potential program achievement, comparison with previous curriculum, cost standard, and so on. Responding to these questions, what is needed is not just an answer, but a series of field verification that will be used as consideration in decision making and quality assurance (Rahman, 2005, Kadaruddin, Arafah, B., Ahmad, D., Kaharuddin, Iska, 2020).

\section{Curriculum Evaluation Model}

Out of many models offered by curriculum experts, practitioners, and researchers, this study offers Process Evaluation Model proposed by Davies (2001). This model is simple enough to do in a relatively short time and by focusing on the processes that occur in the implementation of the curriculum. This model, according to Davies (2001), is suitable to be used by lecturers either individually or in groups or teams.

The first stage in the implementation of Davies model is the description of sub-processes on the reason that the process cannot be obtained from classroom or curriculum investigations. Thus, data collection is done by determining the part of curriculum structure to be evaluated. Furthermore, the 
second stage of Davies' Process Evaluation Model is the determination of an evaluation instrument containing the questions followed by instrument testing and validation to be used in the data collection process. At this stage, all the data obtained are grouped according to pre-defined categories to be analyzed and described. Irrelevant or unnecessary data did not need to be included.

In the final stages, it was done clarifying the factors identified influences the effectiveness of the curriculum. Decisions taken in this evaluation can then be submitted to those who need the results of the review to be followed up. The procedure in this model seems to be more accurate when it is described using the Stake's Countenance Model which involves three evaluation components, namely antecedents (inputs), transactions (processes), and outcomes (findings). However, the overall subcomponents of the three components do not have to be totally incorporated and can be tailored to the needs or focus of the evaluation.

\section{Coverage of Curriculum Evaluation}

The following describes the area of curriculum evaluation coverage in two orientations proposed by Rahman (2005);

\section{Program Evaluation / Curriculum Document (Antecedents)}

Curriculum document has several components, namely rational, vision-mission and objectives, graduate competence, subject structure and credits, planned learning experience, learning strategy, learning appraisal, financing, facilities, infrastructure, and academic calendar. Evaluation of components in curriculum documents can be done by selecting components and sub-components in accordance with the purpose of evaluation.

In the rational or background components, for example, it will be obtained a description of the setting, philosophical foundations, and theoretical basis of the theories and assumptions underlying curriculum development. For these components, evaluation is directed to the suitability of subcomponents with the formulation of other components, especially in the aspect of objectives, graduate competence, course structure, credits, and learning strategies. Likewise, the components of subject structures and credits can be evaluated to determine their effectiveness. Evaluation can also be done by comparing the components of the curriculum document with its implementation in the field. Any form of input to be compared to its implementation is categorized as an antecedents or input subcomponent.

The planning of K-10 PBI that became the focus in this research is the assessment of attitude and the views of lecturers and students on the courses structure and credits presented in the curriculum. Indicators used include their attitudes toward issues related to overlapping of several courses and the courses placement that are assumed to be inadequate with student learning needs, student cognitive development level, link and match concept, and structured and/or conditional lectures.

\section{Evaluation of Curriculum Implementation (Transactions)}

Curriculum evaluation in the context of implementation according to Rahman (2005) is more directed to the conformity of planning with the implementation of the curriculum. Process evaluation in this case is designed and implemented in the implementation of activities. This evaluation includes the identification of implementation procedure problems (Stufflebeam, 1986, Bahar, A. K. 2013).

To reveal the implementation of K-10 PBI, several aspects have been developed as the focus of evaluation as follows: a) assessing the liveliness of students and lecturers in learning with indicators of classroom attendance or out-of-class learning activities; the efforts to manage and monitor learning activities with or without lecturer attendance; and, managing changes to the learning schedule. b) The interaction between lecturers and students in various media related to learning or other academic tasks with the indicators such giving a balanced and fair attention to every student, the willingness of lecturers to interact with students with various possible media, and the willingness of lecturers to provide consultation and tutorial to students with various techniques. c) Assessing the productivity and mastery of lecturers in the preparation of instructional administration, learning materials, learning strategies, delivery of learning including the delivery of objectives and lecture contracts, the use of instructional media, and assignment. d) Assessing lecturer activity in terms of management of learning appraisal with indicators of assessment, value and feedback administration, and remedial teaching.

\section{Curriculum Design}

In general, there are three patterns of organizing curriculum that is most widely used, namely: 1) SubjectCentered Design; 2) Learner-Centered Design; and 3) Problem-Centered Design. These three patterns are described briefly based on Sukmadinata's (2002) view as follows: 


\section{Subject-Centered Design (SCD)}

Subject-Centered Design (SCD) is a curriculum-organizing pattern centered on teaching materials to be presented. SCD curriculum design is composed of a number of subjects categorized into three types, namely Subject Design, Disciplines Design, and Broad Fields Design.

\section{Learner-Centered Design (LCD)}

Unlike the SCD that puts forward the contents of the curriculum, Learner-Centered Design (LCD) prefers students with the assumption that students are organisms that have the potential to act, behave, learn, and develop. On the basis of that, curriculum organizing is based on students' interests, needs and goals.

\section{Problem-Centered Design (PCD)}

PCD is a curriculum design centered on social issues. This curriculum model uses the assumption that as social beings, humans live in one community and experience problems that must be solved together. The curriculum material is lifted from the social problems that are being and will be faced by the students. The ordering patterns of materials are structured according to the needs, interests, and abilities of the students.

\section{Theoretical Framework}

The theoretical framework of this study is illustrated by the scheme in Figure 1. The scheme shows the theoretical framework of the evaluation on K-10 PBI referring to the Disciplines and Broad Fields Design models. This curriculum is applied to students of PBI UIN Alauddin Makassar from 2011 to the present and implemented its usage by lecturers in the department. The curriculum element evaluated is the implementation of the curriculum in the learning process series.

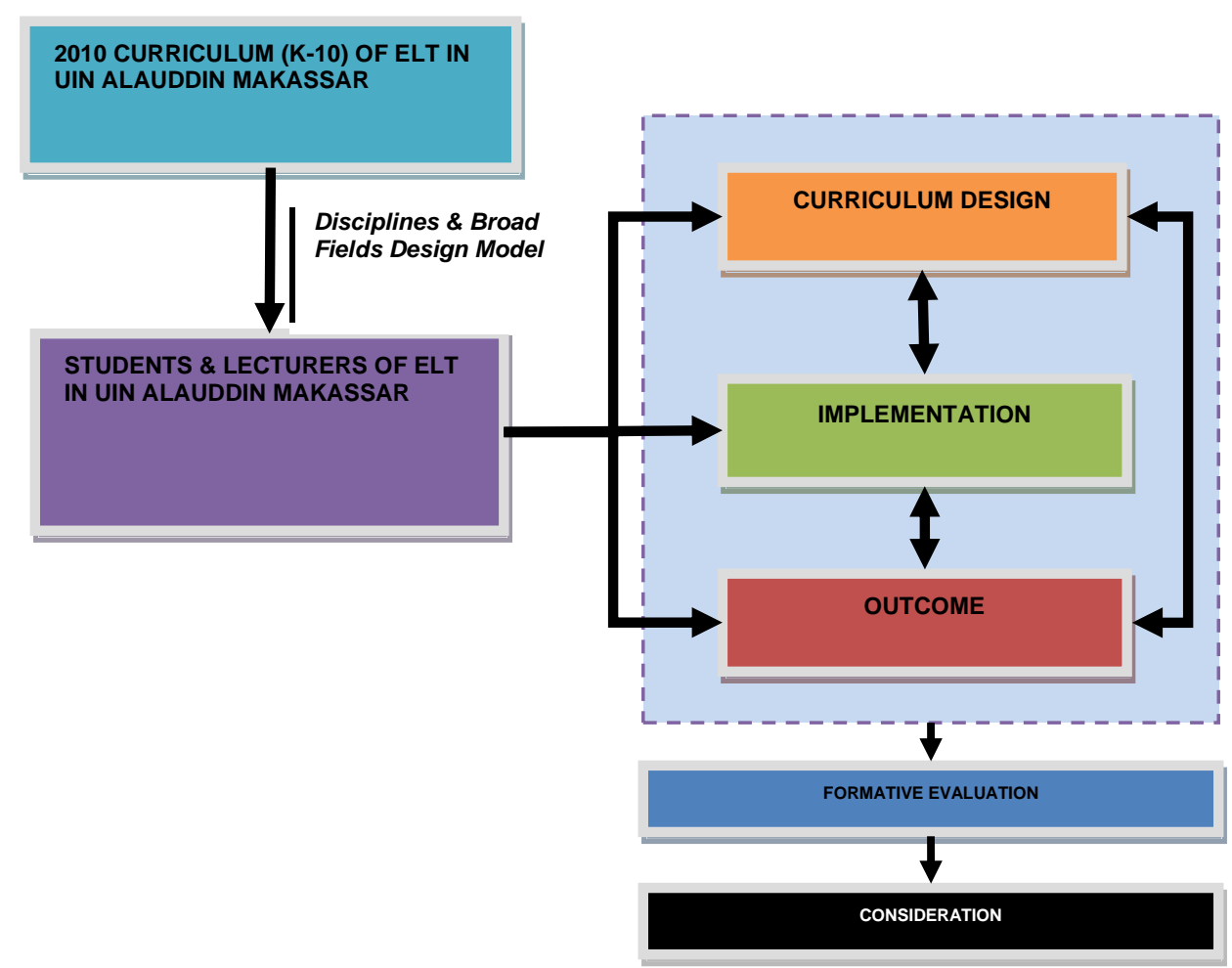

Figure 1. Theoretical Framework

\section{RESEARCH METHOD}

This research is categorized as evaluation research by using a case study method. Stake (cited in Gall \& Gall, 2003: 435) suggests that a case study is interpreted as a form of observation on a particular case rather than the inquiry method used. In addition, a case study falls into qualitative research. In a qualitative research paradigm, the researcher seeks to gain a deep understanding and interpretation of the meaning of a phenomenon (Bogand and Taylor in Moleong, 2000: 3; Ary et al., 2006). Qualitative 
research findings are in the form of descriptive data in the form of sentences (speech/writing), or observed behavior. Furthermore, according to Maykut and Morehouse (1994: 201), the purpose of qualitative research is to find patterns appearing after close observation, careful documentation, and careful analysis.

The evaluation design used in this research is the evaluation design of Stake's Countenance Model developed by Robert E. Stake (adopted from Sukirman et al., 2017). The evaluation design form applied in this research as follows:

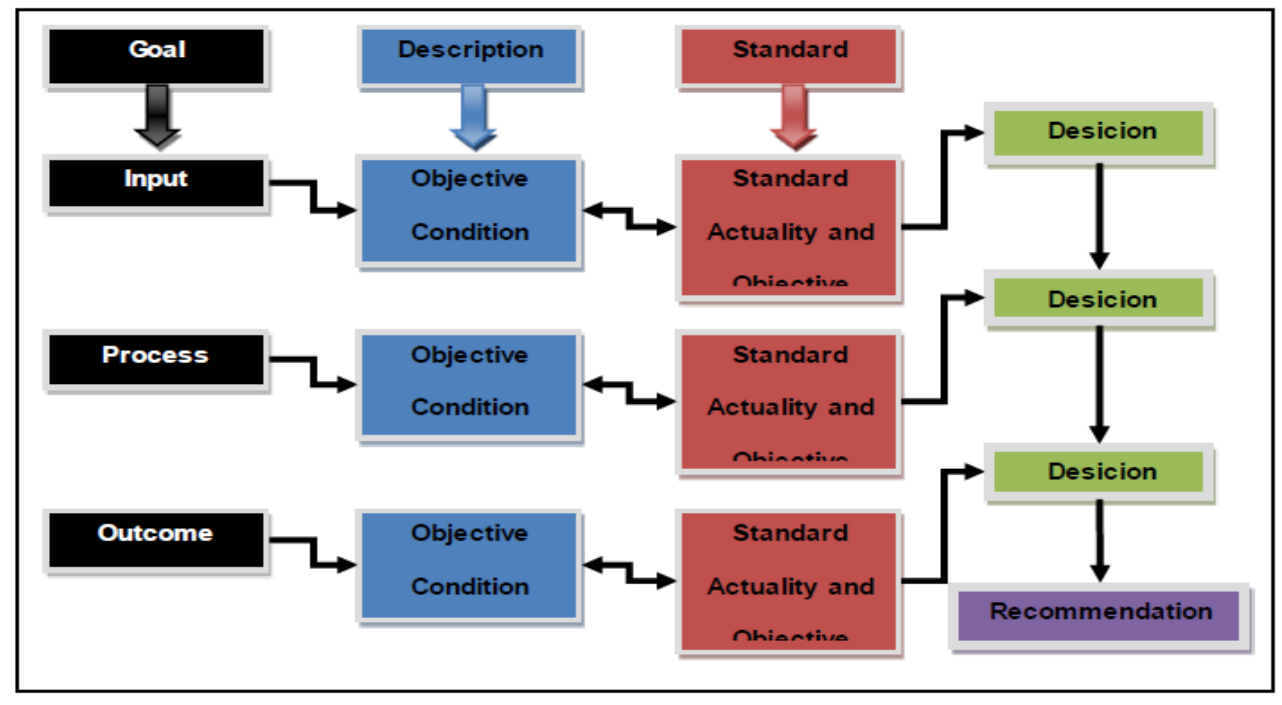

Figure 2. Evaluation Design (Adopted from Sukirman et al., 2017)

The design shows that the findings of data from the three components (input, process, and results) will be compared with the achievement standard. Decision making Implementation on each component is categorized into three levels, namely: low, medium, and high. This categorization is based on a comparison of the objective standard of each evaluation focus with a minimum conformity rate of $85 \%(\geq 85 \%)$.

This curriculum evaluation study was conducted in English Education Department at the Alauddin State Islamic University of Makassar in accordance with the needs of department organizers for the ongoing curriculum improvement. The research started from February to April 2017. Furthermore, the selection of informants was done purposively based on the intent and purpose of the research. Based on the research criteria, the key informants in this study were shown in Table 1:

Table 1. Distribution of Key Informants

\begin{tabular}{|l|l|l|l|}
\hline No. & Key Informants & F & $\mathbf{( \% )}$ \\
\hline 1 & Department Head & 1 & 1.19 \\
\hline 2 & Secretary & 1 & 1.19 \\
\hline 3 & Civil Servant Lecturers & 10 & 11.90 \\
\hline 4 & Non-Civil Servant Lecturers & 5 & 5.95 \\
\hline 5 & Contracted Lecturers & 5 & 5.95 \\
\hline 6 & Staff & 2 & 2.38 \\
\hline 7 & Students & 60 & 71.43 \\
\hline Total & $\mathbf{8 4}$ & $\mathbf{1 0 0}$ \\
\hline
\end{tabular}

The key variable in this study was the implementation of the curriculum. Furthermore, to evaluate the implementation, the researcher collected data through observation techniques and questionnaires. Observation technique was done by observing the implementation of learning in the classroom on 22 courses that run in the odd semester of 2013 for the intake in 2012 and 2013. The instrument used was learning implementation observation formats. The use of questionnaires distributed to 60 randomly selected students was used to collect data on the objective assessment of students on the implementation of learning in the course that has been determined. The data collected by the procedures were used to answer the research question 
Generally, the quantitative data obtained from observation checklist, behavioral assessments, student learning outcome appraisal formats, and attitude questionnaires were analyzed using descriptive statistics. Then, qualitative data obtained from the interviews were analyzed, presented, interpreted, and discussed qualitatively using the most coherent expression. In addition, the data obtained from documentation techniques using observational checklists were analyzed by descriptive statistics (percentages). Scoring was done by summing the response for each subscale then written in percent (\%). The percentage of subsequent scores was compared with the score of the interval with the conformity standard on three levels as in Table 2 below:

Table 2. Value of Congruence Score

\begin{tabular}{|l|l|}
\hline Score in Percent (\%) & Qualification of Conformity \\
\hline $67-100$ & High \\
\hline $34-66$ & Medium \\
\hline $0-33$ & Low \\
\hline
\end{tabular}

Actuality decision making techniques at each stage of evaluation or aspect were performed by measuring at each evaluation focus summarized in matrices adapted in Case-Order Effect Matrix (Sabarguna, 2005: 27). This matrix model has a characteristic that displays the effect of comparison between the objective standard in the form of predefined normative standard criteria compared with the objective intensity of real recording in the field. The comparison would result in the conclusion effect that is the decision actuality on each case observed.

The data obtained from the questionnaires conducted by students and lecturers were analyzed in two ways. The first way was done by descriptive analysis by summing the respondent's answers in the same category to get the dominant view and the percentage. The second way was done by assessing the dominant answer with score 1 for acceptance of the existing conditions, and score 0 to reject the existing conditions. The number of scores on each component was then calculated the percentage to determine the assessment of component feasibility standards, whether worth maintaining or needing changes. Table 3 below was used to determine the feasibility standard:

Table 3. Eligibility Standards Score

\begin{tabular}{|l|l|}
\hline Score in Percent (\%) & Eligibility Standards \\
\hline $81-100$ & Very Eligible \\
\hline $61-80$ & Eligible \\
\hline $41-60$ & Less Eligible \\
\hline $21-40$ & Ineligible \\
\hline $0-20$ & Totally Ineligible \\
\hline
\end{tabular}

\section{FINDINGS AND DISCUSSION}

\section{Curriculum Implementation Description}

Curriculum implementation evaluation applied 20 descriptors containing the curriculum design implementation including the lecturers' presence as well as the assessment model of student competence. The following was summarized data from the curriculum implementation evaluation conducted with direct observation by students and interviews with the head of department:

Table 4. Summary of Curriculum Implementation Evaluation Data

\begin{tabular}{|l|l|l|l|l|l|}
\hline No. & Indictors & Score & $\begin{array}{l}\text { Ideal } \\
\text { Score }\end{array}$ & \% & $\begin{array}{l}\text { Conformity } \\
\text { Level }\end{array}$ \\
\hline 1 & Lecturers' Presence & & & & \\
\hline & a. Attendance Monitoring & 2 & 4 & 50 & Medium \\
\hline & b. Absence Confirmation & 2 & 4 & 50 & Medium \\
\hline & c. Absence Replacement Mechanism & 1 & 4 & 25 & Low \\
\hline & d. Lecture Schedule Changes & 4 & 4 & 100 & High \\
\hline 2 & Learning Process & & & & \\
\hline & a. Designing Course Outline & 1 & 4 & 25 & Low \\
\hline & b. Learning Objectives Discussion & 2 & 4 & 50 & Medium \\
\hline & c. Course Contract & 4 & 4 & 100 & High \\
\hline
\end{tabular}




\begin{tabular}{|l|l|l|l|l|l|}
\hline & d. The Use of Materials Development & 1 & 4 & 25 & Low \\
\hline & e. The Use of Other Source Materials & 3 & 4 & 75 & High \\
\hline $\begin{array}{l}\text { f. The Use of Learning Methods / } \\
\text { Techniques }\end{array}$ & 1 & 4 & 25 & Low \\
\hline 3 & g. The Use of Teaching Media & 3 & 4 & 75 & High \\
\hline $\begin{array}{l}\text { Learning Assessment } \\
\text { a. } \text { Students' Attendance }\end{array}$ & 4 & 4 & 100 & High \\
\hline b. Assessment Documents & 1 & 4 & 25 & Low \\
\hline & c. Structured Individual Tasks & 2 & 4 & 50 & Medium \\
\hline $\begin{array}{l}\text { d. Unstructured Individual Tasks } \\
\text { e. Scores and Feedback on Students' } \\
\text { Works }\end{array}$ & 2 & 4 & 4 & 25 & Ledium \\
\hline 4 & $\begin{array}{l}\text { f. Returning Students' Work } \\
\text { Student Services }\end{array}$ & 1 & 4 & 25 & Low \\
\hline $\begin{array}{l}\text { a. Lecturers' Readiness to be } \\
\text { Contacted by Students }\end{array}$ & 4 & 4 & 100 & High \\
\hline $\begin{array}{l}\text { b. Structured and Unstructured } \\
\text { Supervision }\end{array}$ & 0 & 4 & 0 & Low \\
\hline c. Remedial & 0 & 4 & 0 & Low \\
\hline TOTAL $\quad \mathbf{3 9}$ & $\mathbf{8 0}$ & $\mathbf{4 8 , 7 5 \%}$ & Medium \\
\hline
\end{tabular}

\section{Lecturers' Presence}

\section{Attendance Monitoring}

Based on the data obtained from the department, the lecturers' attendance in the lecture had reached an average of $98.32 \%$ per semester. It meant that there was still about $1.68 \%$ that had not been met. The amount was already more than the achievement target of at least $85 \%$ per semester. The monitoring conducted by the department was still in the conventional format by controlling and recording the lecturers' attendance in the classroom during the teaching hours and researching the attendance that had been provided by the academic. However, the structured and unstructured guidance activities were still missing from the monitoring and had not yet been formally documented.

\section{Absence Confirmation}

So far, no written rules had been found related to the mechanism of lecturers' absenteeism, so in practice students often wait on campus without any certainty. In some lecture contracts, it was found that if the lecturer does not come after 15 minutes from the schedule, the student is allowed to leave the place without having to confirm to the lecturer. However, it was found from the observations and student reports that the lecturer phenomenon comes after 15 minutes and performs the usual learning, monitors student attendance, and exploits those who have already come home. Such phenomena need not occur if the department has issued written rules regarding absenteeism understood by lecturers and students. In other words, written rules displayed on the walls of the classroom had not been done by the department.

\section{Absence Replacement Mechanism}

No document has been found containing the rules of lecturers' absence change mechanism. From the verbal statement of the department, so far there had been many reports from students regarding the lecturers' absence more than two meetings. However, the efforts to resolve the issue are still at the point of advice or verbal reprimands. Further, it was explained that the replacement of lecturers was very difficult to do if the lecture had been running until the middle of the semester. The difficulty was mainly on the lack of permanent lecturers who had a scientific background in the subjects.

\section{Lecture Schedule Changes}

Changes in class schedules are closely related to the availability and/or capacity of the room compared to the number of students in PBI department. Nevertheless, so far the mechanism of changing lecture schedule did not have a serious problem because the requirement of the schedule change must be with the approval of the students and lecturers as well as known by the department for the monitoring purpose. 


\section{Learning Process \\ Designing Course Outline}

So far, one of the weaknesses of the implementation of the learning process in PBI was the lack of lecturers' preparation in learning materials and media. From the observation of the department, no lecturer had been actively and continuously preparing the course outline requested by the department. In the absence of course outline that should be deposited to the department at the beginning of the course, the department will by itself be difficult to measure the learning achievements mandated in the curriculum. In addition, lecturer learning activities in the classroom are difficult to be observed, especially in the aspect of the objectives to be achieved, the accuracy of choice of strategies and learning methods that lead to the achievement of learning objectives, and assessment model activity used in unlocking student potential.

It cannot be allowed to continue without change. The department must firmly ask each lecturer to include their course outline at the beginning of the lesson or a week after receiving the letter of learning assignment. If this is left unchecked, then the measurement of the attainment of the charge or the target of curriculum will only end with the average calculation of the student's GPA or no more than the forecast-only estimate.

\section{Discussing the Learning Objectives and the Course Contracts}

The learning objectives and course contracts are two different things. The learning objectives formulated in curriculum should be discussed to the students at the beginning of each course. It is important that students know what competencies will be achieved after the learning is over. Achieving the learning objectives is a major aspect that underlies the whole set of learning activities for one competency. This has been done by almost all lecturers either directly or indirectly. However, no document shows the basic competencies to be achieved because most lecturers do not design course outline.

As for the course contract, all lecturers have completed the document and negotiated with the student at the beginning of the lecture. Course contract is a document developed by lecturers containing rules that bind students and lecturers in lectures in certain courses. It was disseminated to students on the first day of the course and agreed by both parties. Especially for course contract, the implementation was in accordance with the rules.

\section{Teaching Materials Use}

Based on the data obtained from the students, lecturers, and the head of department, among lecturers had been using the adoption, adaptation, and even developed materials. Unfortunately, in terms of quantity the amount was still very small compared to the number of courses presented. In addition, teaching materials can also be obtained from other available sources, either lecturers' private-owned materials or available in the campus library. Related to this, most lecturers use books or journals that are already available because they consider it easier than if they have to develop their own teaching materials. Of course this is not wrong if it refers to the guidance of Higher Education Curriculum set by BSNP. Nevertheless, the creativity of lecturers was still very much expected considering the teaching material model with the module or the adoption will slightly ease the students in terms of the cost of procurement of teaching materials.

\section{Learning Method or Technique}

From classroom observations by researchers and students, most lecturers still used four mainstream methods, namely Lecture-Based (Lecture), Small Group Discussion, Presentation, and Questions \& Answers. The response of the lecturers was not very varied as it was generally only stated that it was adapted learning materials. The students' recognition since the beginning of the semester to the running semester, lecturers used more methods in forms of discussion and lecture. In this case, the students were given teaching materials in groups and then different groups each week will be the presenter of the material. Lecturers provide input related to questions that cannot be answered by the presenter group.

\section{The Use of Learning Media}

In terms of the use of teaching media, the findings indicate that most lecturers had used computer-based or IT tools. The use of power-point from the Microsoft program was no a new thing. Students also took part in the program and since Campus II had been equipped with internet facility, some lecturers used it as teaching media. This is certainly encouraging because in this era lecturers and students are still following the pace of development and no longer used traditional media. 


\section{Learning Assessment}

\section{Student Presence}

The progress achieved by PBI and other majors dealing with the students' presence in the lecture process seemed to be disciplined and leave the laziness. Since the enactment of the absenteeism discipline of the last two years with the condition of not attending lectures three times, the students were not given the opportunity to follow the final examination. This condition changes the old paradigm that made the students motivated extrinsically to be active and participate in face-to-face learning activities in the classroom.

Nevertheless, there were still some students who had not shown any change on the grounds that they may ask for waivers at the time for study completion. This created a bad precedent if the lecturers and the department managers gave freedom to the students with the wrong policy model. It was undeniable that such a practice was still found but in its development had begun to be eroded so that students by themselves must change their mindset.

\section{Assessment Document}

So far, the appraisal document in the department was only a summative assessment of the results of students' final examination. Weekly appraisal documents, both process and outcome of lectures, structured self-tasks, and unstructured self-tasks had not been completed by lecturers. So far, documenting assessments of weekly appraisals self-tasks, mid-test, final test, and other scores were thoroughly computed fingers. The findings of interviews from the department acknowledged that it was entirely submitted to the respective lecturers and so far the lecturer had not been recommended to submit the scores periodically or at least at the end of the semester. The lecturers only submitted the finals scores with the printed-scoring format by the academic bureau.

\section{Assigning Structured Individual Tasks}

Assigning self-structured tasks is one of the learning activities in form of deepening material for students designed by lecturers to achieve certain competencies. The time for completing the assignment was determined by the lecturers. Then, in this activity there was no direct interaction between the lecturer and the students. Such assignments were generally done by lecturers every week or period. This was not something new or unfamiliar to the lecturers and students of PBI, but in practice there were still many lecturers who had not planned or put in their course outline. As a result, assigning self-structured tasks seems like impromptu. By itself, what can be suggested is to make a plan and be documented in the course outline so that the activity is measurable.

\section{Assigning Unstructured Individual Tasks}

Assigning unstructured individual task is a learning activity in the form of deepening material for students designed by lecturers to achieve certain competencies. The time in completing the assignment was generally determined by the students. Then, in the process there was no direct interaction between lecturers and students. This kind of activity was also basically done by lecturers but with the difference in the timing in collecting the tasks that should be determined by the students - it is much determined by the lecturers although it is stated anytime as long as collected before final test. Similar to the structured, the lecturer also had not planned or put them in their course outline.

\section{Scoring, Grading, and Providing Feedback on Students' Work}

Based on the observations and assessments conducted on students' tasks, it was found that many lecturers did not examine and assess the tasks assigned to students, especially in the form of papers. Most of the tasks submitted by the students with all the efforts were only stacked on the side of the table that was not even touched at all. This is of course a major concern for the department to monitor the lecturers' performance in checking students' work or projects. What can be done is to ask students to report to the department if there is a lecturer who does not check and give scores, grades, and feedback on student duties.

\section{Returning Students' Work}

The written assignments or projects that had been undertaken by the students should be returned to the student after reviewed, given scores, assessed, and given feedback. The students generally acknowledged that the duties they submitted at the request of lecturers in the form of papers were very rarely returned to them. They never see the form of their duties even after collected they tend to forget. This happens 
because the negligence of some lecturers does not return students' duties after asking the students to finish it with a certain grace deadline. Nevertheless, there were some lecturers who carefully examine, score, rate, and give feedback and return it to the students for completion. This implies the need for the department to monitor the learning activities by examining the completeness of the lecturer's administration including requesting a sample of duties to students who had been examined and returned.

\section{Student Services}

Service to students who have problems both academic and non-academic basically should be done by a team of department counselors or at the faculty level. If due to limited resources then the campus has not been able to provide it, then the academic advisor must take over the task. Nevertheless, it is possible that lecturers can participate in providing consultation services to students who have problems or specific cases in the lecture.

\section{Lecturer's Readiness to be Contacted by Students}

Related to the academic services for students, the lecturers need to spend time for students for consultation purposes. The implementation mechanism is submitted to each lecturer according to the competence and their ample time. Under conditions when students need such assistance, lecturers are at least willing to be contacted by students either directly or with the media that allows the consultation done. In the implementation, it was still found some lecturers who refuse to be contacted by students except in the campus environment by first making an agreement. The problems are some cases found difficult facts for lecturers to spend time in the hours of college because of busy teaching and guiding thesis or perform other types of assignments. The flexibility of lecturers is needed in that context so that students gain a sense of security in order to continue the learning tasks.

\section{Structured and Unstructured Guidance}

So far, structured and unstructured guidance are still difficult to measure because the lecturers have not been able to demonstrate the documentation of the planning and implementation and assessment of the independent mentoring activities. Therefore, it is strongly recommended that lecturers once again plan their learning activities with the guidance of BSNP for the learning implementation in universities.

\section{Remedial Learning}

The remedial learning adopting the complete learning model or mastery learning in competence-based curriculum has not been done by the lecturer. Remedial learning is given to students who fail to achieve goals on a particular base competence. Remedial learning is not a 'retest' but rather a special lesson given to a maximum of two meetings to complete a certain basic competence that the students have not understood yet. Learning is not done in normal classes, but it is done in separate classes with methods and learning techniques tailored to the characteristics of individuals who have problems.

\section{CONCLUSIONS AND SUGGESTION}

At the transactions level, the level of compliance between objective conditions with objective standard/objective quality for the overall curriculum implementation component was rated 'Medium' $(48.75 \%)$ which means that some subcomponents still required limited changes or revisions in accordance with the instructions of BSNP. Then, Formative evaluation on curriculum at department level needs to be done periodically (every year) to ensure the quality of the program and to anticipate changes and developments in the needs of the world of work.

\section{REFERENCES}

Ahmad, D. (2012). Curriculum Reform: An overview of the English Teaching in Indonesian context. Alauddin University Press.

Ahmad, D. (2016, August). Exploring Policymakers' and Teacher Perceptions and Interpreatations in Makassar Towards Curriculum 2013 (A Mixed-Design Study). In The Asian EFL Journal Second Language Acquisition-Academic Research TESOL Indonesia International Conference Edition March 2017 (pp. 225-235). English Language Education Publishing.

Andi, K., \& Arafah, B. (2017). Using needs analysis to develop English teaching materials in initial speaking skills for Indonesian college students of English. The Turkish Online Journal of Design, Art and Communication (TOJDAC), Special Edition, 419-436. 
Arafah, B., \& Kaharuddin, (2019). The Representation of Complaints in English and Indonesian Discourses. Opción, 35, 501-517.

Arafah, B., Thayyib, M., Kaharuddin, \& Sahib, H. (2020). An anthropological linguistic study on Maccera' Bulung ritual, Opción, 36, (27), 1592-1606

Ary, D., Jacobs, L. C., Razavieh, A. and Sorensen C. (2006). Introduction to Research in Education, 7th ed. Australia: Thomson Wadsworth.

Bahar, A. K. (2013). The Communicative Competence-Based English Language Teaching. Yogyakarta: TrustMedia.

Bahar, A. K., \& Latif, I. (2019). Society-based English community (sobat): EFL learners'strategy in learning and practicing English outside the walls. Jurnal ilmu budaya, 7(2), 255-265.

Brown, J. D. (1995). The Elements of Language Curriculum. A systematic approach to Language Development. New York: Heinle\&Heinle Publishers.

. (1989). "Language Program Evaluation: A Synthesis of Existing Possibilities." in R. K. Johnson (Ed.), The Second Language Curriculum (222-241). Cambridge: Cambridge University Press.

Badan Standar Nasional Pendidikan. (2010). Standar Isi Pendidikan Tinggi. Jakarta: BSNP.

Candlin, C. N. (1984). "Syllabus Design as A Critical Process." In C. J. Brumfit (Ed.), General English Syllabus Design (ELT Documents No. 118, 29-46). London, UK: Pergamon Press \& The British Council.

Davies, E. (2001). Teachers as Curriculum Evaluators. Sydney: George Alien and Unwin.

Gall, M.D., and Gall, J.P. (2003). Educational Research: An Introduction. New York: Pearson.

Ismail, A. H. S., Halidin, A., \& Amzah, N, Kaharuddin (2020). Paraphrasing technique to develop skill for English writing among Indonesian college students of English. Systematic Reviews in Pharmacy, 11(11), 291-297.

Kaharuddin, A. (2018). The communicative grammar translation method: a practical method to teach communication skills of English. ETERNAL (English, Teaching, Learning, and Research Journal), $4(2), 232-254$.

Kaharuddin, Hikmawati, Arafah, B. (2019). Needs Analysis on English for Vocational Purpose for Students of Hospitality Department. KnE Social Sciences, 344-387.

Kaharuddin., \& Hasyim, M. (2020). The Speech Act of Complaint: Socio-Cultural Competence Used by Native Speakers of English and Indonesian. International Journal of Psychosocial Rehabilitation, 24(6), 14016-14028. doi: 10.37200/ijpr/v24I6/pr261351

Kaharuddin, K., \& Rahmadana, A. (2020). Problem-Based Group Discussion: An Effective ELT Technique to Improve Vocational High School Students' Transactional Speaking Skills. Jurnal Ilmu Budaya, $8(2), 247-258$

Kadaruddin, Arafah, B., Ahmad, D., Kaharuddin, Iska. (2020). Word Wall Media: An Effective Teaching Technique to Enrich Students' Vocabulary in Secondary Level of Education, International Journal of Advanced Science and Technology, 29 (5), 13228-13242.

Kaharuddin, Ahmad, D, Mardiana, Rusni (2020) Contributions of Technology, Culture, And Attitude To English Learning Motivation During Covid -19 Outbreaks. Systematic Reviews in Pharmacy, 11 (11), 76-84. doi:10.31838/srp.2020.11.13

Marsh, C. (2004). Key Concepts for Understanding Curriculum (3rd ed.). London and New York: Routledge Falmer.

Maykut, P. and Morehouse, R. (1994). Beginning Qualitative Research: A Philosophic and Practical Guide. London: Falmer Press.

Moleong, L. J. (2000). Metodologi Penelitian Kualitatif. Bandung: PT Remaja Rosdakarya.

Nasution, A. (2004). Metode Research. Jakarta: Bumi Aksara.

Nichols, B., Shidaker, S., Johnson, G., and Singer, K. (2006). Managing Curriculum and Assessment. A Practitioner's Guide. Ohio: Linworth Books.

Rahman, L. (2005). "Findings and Lessons Learned: Scaling up of Reproductive Health Curriculum in Youth Training Courses," Paper Presentation at the Dissemination Seminar of Population Council's FRONTIERS Program and Department of Youth Development, Ministry of Youth and Sports, Government of the People's Republic of Bangladesh, Dhaka 23 March.

Sabarguna, S. B. (2005). Analisis Data Kualitatif. Jakarta: UI Press.

Simons, H. (ed.). (1987). Towards a Science of the Singular: Essays about Case Study in Educational Research and Evaluation. Occasional Publications No. I0. Norwich: University of East Anglia, Centre for Applied Research in Education.

Stake. R. E. (1967). "The Countenance of Educational Evaluation”. Teachers College Record. 68 (7): 523 540.

Stenhouse, L. (1975). An Introduction to Curriculum Research and Development, London: Heinemann. 
Stufflebeam, D. (1986). Educational Evaluation and Decision Making. New York: Peacock.

Sukirman, Ahmad, D., \& Mardiana. (2017). Formative Evaluation on Course Structure and Credits at English Language Teaching Curriculum. Arab World English Journal, 8(1): 322-338

Sukmadinata, N.S. (2002). Pengembangan Kurikum; Teori and Praktek. Bandung: P.T. Remaja Rosdakarya. Yassi, A. H. \& Kaharuddin (2018). Syllabus Design Of English Language Teaching. Prenada Media. 